\title{
The Construction of Failure and Success Concepts in K-12 ICT Integration
}

\author{
Zvia Elgali \\ Science, Technology and \\ Society Program, \\ Bar-Ilan University, Israel \\ zvia.elgali@live.biu.ac.il
}

\author{
Yoram M. Kalman \\ Department of Management \\ and Economics, The Open \\ University of Israel, Israel
}

\begin{abstract}
The integration of information and communication technologies (ICT) into educational systems is one of the greatest challenges faced by educators and policymakers. Despite high-profile efforts and significant investments of resources, ICT integration programs in the K-12 system generate plenty of talk about failure. This study explores the construction of these failure and success concepts in the Israeli national ICT integration program. An application of actor-network theory (ANT) to the national program, as well as to a local ICT integration program, reveals significant similarities and differences in the networks of the two programs. We propose that five categories of these differences point to possible causes for the increased level of talk of failure in the national program. The ANT findings suggest further analysis, utilizing the social construction of technology (SCOT) approach to study the interpretive flexibility of the relevant social groups involved in the ICT integration programs. The SCOT analysis suggests that the interpretive flexibility of the different groups is a source of disagreements around the ICT integration programs.
\end{abstract}

Keywords: actor-network theory, social construction of technology, K-12 education, ICT integration

\section{Introduction}

"Since the invention of the motion picture, teachers have been intrigued by the potential of technology" (Hew \& Brush, 2007, p. 224). Despite the great promise of technologies, the challenge of effectively harnessing technologies to benefit learners, educators, and administrators is still great. This challenge is most apparent in regards to efforts by policymakers to integrate information and communication technologies (ICTs) in schools. Despite significant efforts and resources invested in ICT integration programs in various school systems, we find a disproportionate number of re-

Material published as part of this publication, either on-line or in print, is copyrighted by the Informing Science Institute. Permission to make digital or paper copy of part or all of these works for personal or classroom use is granted without fee provided that the copies are not made or distributed for profit or commercial advantage AND that copies 1) bear this notice in full and 2) give the full citation on the first page. It is permissible to abstract these works so long as credit is given. To copy in all other cases or to republish or to post on a server or to redistribute to lists requires specific permission and payment of a fee. Contact Publisher@InformingScience.org to request redistribution permission. ports of failure of such programs (e.g., Cuban, 2010; Wild, 2006). One of the labels this phenomenon has received is technological paradox (Salomon, 2000), a term that describes how the more deeply a technology is integrated in learning and teaching, the less it influences the educational system in general, and the learner in particular. The motivation for this study is the abundance of reports of failure of ICT integration pro-

\section{Editor: Alex Koohang}

An earlier, shorter version of this paper was presented at the Chais conference 2010, in Raanana, Israel, and included in Y. Eshet-Alkalai, A. Caspi, S. Eden, N. Geri, \& Y. Yair (Eds.), Proceedings of the Chais conference on instructional technologies research 2010: Learning in the technological era. Raanana: The Open University of Israel. http://www.openu.ac.il/research center eng/conferences.html 
grams. Specifically, this study explores the construction of the failure and success concepts in the national ICT integration project in the Israeli K-12 educational system (Chen, 2006; Melamed, 2008; Zinder, 2006).

Educational researchers have studied the successes and failures of ICT integration projects through the lens of disciplines such as educational management and educational innovation (e.g., (Chen, 2006; Kozma, 2003; Law, Pelgrum, \& Plomp, 2008). In this study we attempt to apply the tools and insights of science and technology studies (STS) to explore these same questions through a different lens.

STS is a discipline that utilizes science anthropology, history of science and technology, and philosophy. STS researchers explore the social, historical, and philosophical origins of scientific and technological developments, using constructivist models which express the interrelationships between science, technology, and sociology (Giere, 2006; Pinch 1993). STS is thus expected to shed new light on this question, since it utilizes research methods and applies models that are not a part of the toolkit of mainstream educational researchers who study ICT integration.

The two STS approaches used in this study are actor-network theory (ANT) and social construction of technology (SCOT). ANT is a theoretical framework used in STS to demonstrate the way technological artifacts are constructed in society. Under this framework, the actants (both human and non-human entities) are identified, and networks in which they are embedded are explored, in order to identify ways in which social context is bound up with the different actants (Latour \& Woolgar, 1986). One of the significant advantages of ANT in relation to alternative approaches to understanding technology-rich settings is that it treats both people and technological artifacts (humans and non-humans) symmetrically and thus can expose relationships and contexts which are more difficult to detect using other approaches (Doolin \& Lowe, 2002; Tatnall \& Gilding, 1999).

It is important to note that despite the fact that ANT studies a socially embedded network, it should not be confused with social network analysis (SNA). In a paper that focuses on common misunderstandings of ANT, Latour (1996) emphasizes that "the actor network theory... has very little to do with the study of social networks" (pg. 2). Knox, Savage, and Harvey (2006) elaborate on the common origins of the network approaches in social network analysis and in social anthropology. They then go on and emphasize that the former is a method employed by predominantly quantitative social scientists, while the latter is a qualitative method used by social anthropologists.

SCOT is an approach which studies the development of technological artifacts through the identification of relevant social groups. A relevant social group is a group whose members all "share the same set of meanings attached to the same artefact" (Pinch \& Bijker, 1984, pg. 414). This so called interpretative flexibility is then used to explain the different trajectories that technological developments have taken (Genus \& Coles, 2007; Klebl, 2008; Pinch \& Bijker, 1984).

\section{Research Question}

Traditional research of the success and failure of ICT integration programs in educational settings focuses on the variables that contribute to such success or failure. STS offers an alternative to this reductionist approach. Rather than looking for cause and effect relationships, it aims to unveil patterns and interrelationships that construct the technological artifact, in a social context. A key method STS researchers use to reveal these patterns and interrelationships is the exploration of discourse about the research topic. Our goal is to reveal patterns and relationships that elucidate the failure and success of ICT integration programs in educational systems, and thus our research question focuses on the discourse created in relation to such integration programs. The research question is: 
How are the concepts of failure and success constructed in discourse related to a national ICT integration program in a K-12 educational system?

\section{Method}

\section{Sources}

We gathered documents relating to ICT integration programs in the Israeli K-12 system. This corpus included newspaper articles and other mass media reports, evaluation reports, committee protocols from the parliament and the Ministry of Education, power point files of presentations by policy makers in the Israeli Ministry of Education and by education researchers, ICT integration projects' websites, blog posts of ICT integration experts, academic articles, press releases by corporations and non-profits, e-mail exchanges, and transcripts of interviews with a middle school principle, an ICT coordinator in the Ministry of Education, and a policy maker involved with ICT integration in education. The analysis was carried out by a researcher who is affiliated with several ICT integration programs in Israel's educational system, including the small municipal program that has been used for comparison purposes in the ANT analysis. In total, the number of individual resources analyzed in this study is 124 .

\section{Actor Network Theory (ANT) Analysis}

The actor network theory based analysis employed in this study is based on the work of Latour and his colleagues. The term "Actor network theory" was devised by Michel Callon in 1982 (Latour, 2004; Latour \& Woolgar, 1986; Law, 2007) and refers to a theoretical framework that describes the world as a network of hybrid (social and technological) actants. In this network it is possible to study both people and technologies using the same tools. ANT's postulation that the social and technological should be studied on an equal footing is most productive when applied to cases in which the social and technological are embedded in each other (e.g., Elbanna, 2009).

The analysis was based on a comparison between the discourse on failure and success associated with the national program and the discourse that surrounded a second ICT integration program. This second integration program was a small-scale municipal program. The discourse associated with this program was more neutral and included more references to success and fewer references to failure. An ANT analysis of each of the two programs was followed by a comparison of the two networks. Significant similarities and differences between the two networks were identified, and several of those which might explain the construction of the failure and success concepts in the national program are highlighted and discussed.

The texts were analyzed for references to failure, as well as for references to success. Following several iterations of analysis, two networks have been drawn. In addition, due to the large number of actants and possible relationships, a two-dimensional matrix was used to explore all possible relationships between each pair of actants.

\section{Social Construction of Technology (SCOT) Analysis}

The findings of the ANT analysis revealed interesting relationships between actants, relationships that reflected the interpretive flexibility of the relevant social groups the actants belong to. This led to a SCOT analysis. In the analysis, the same corpus was used to analyze the discourse of each of the relevant social groups. As expected, we found evidence for highly divergent interpretive flexibility. Most interesting for the topic of failure and success, we found several cases in which the same ICT artifact could be depicted as either positive and supportive of the educational system's goals or as negative and not supportive of these goals. Since the picture that emerged was highly complex, we chose then to focus on the interpretive flexibility regarding a single edu- 
cational ICT artifact, the interactive whiteboard (IWB). In this analysis, the corpus sources were augmented by reports on IWB usage in other countries (Armstrong, Barnes, Sutherland, Curran, Mills, \& Thompson, 2005; Hall \& Higgins, 2005; Lewin, Somekh, \& Steadman, 2008).

\section{Results and Discussion}

\section{ANT Analysis}

An outline of the networks of the two programs is presented in Figures 1 and 2. For presentational reasons, the outline shows only the names of the actants, and the existence of uni- or bidirectional relationships. A relationship between two actants was noted when there was evidence for the existence of an ICT related connection between the two actants. Such connections include communication, and the transfer of resources either only uni-directionally (from one actant to the other), or bi-directionally. A comparison between the actants and networks of the national program and of the municipal program revealed similarities, as well as many differences. In this section we describe the differences which are most likely to shed light on variations in the construction of the concepts of failure and success of the programs.

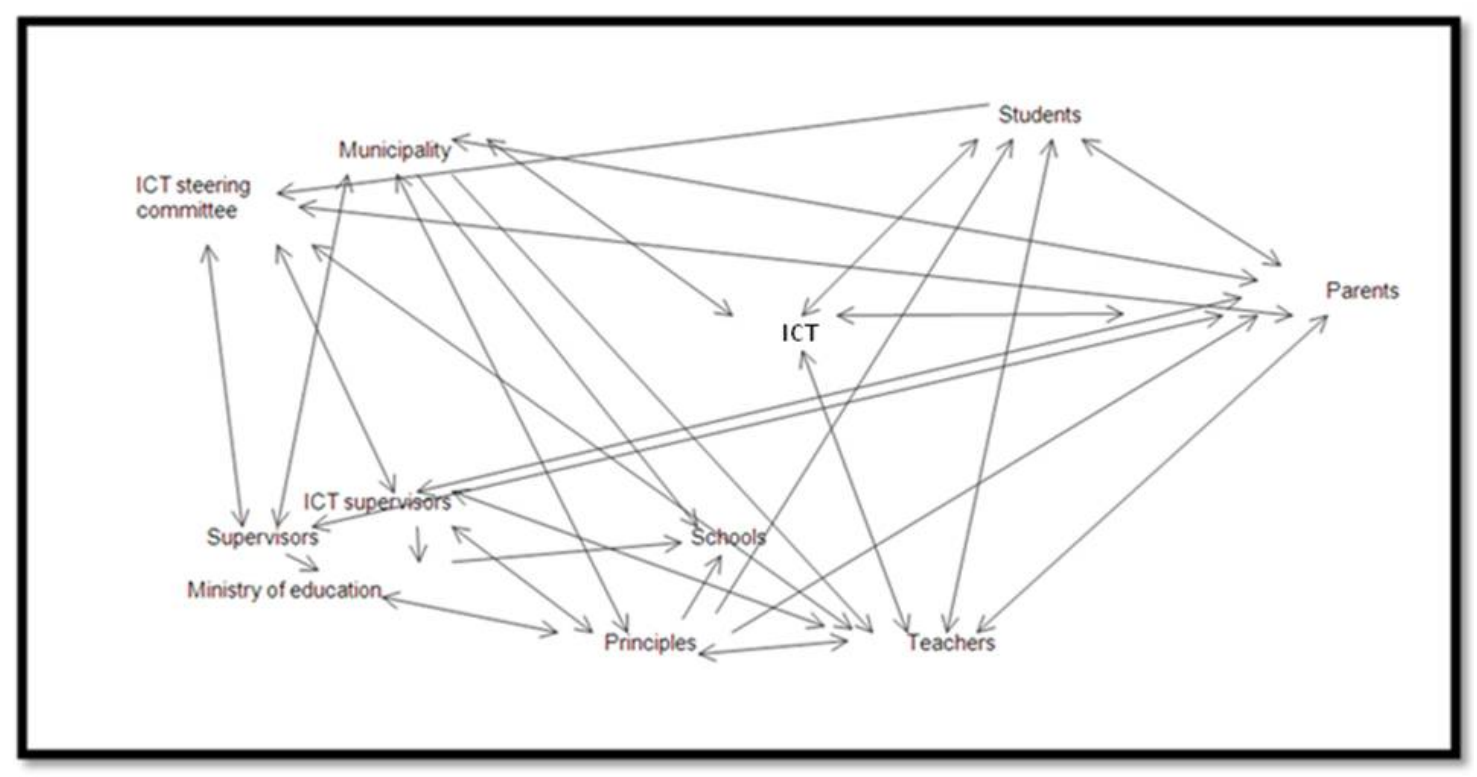

Figure 1: Municipal ICT program network 


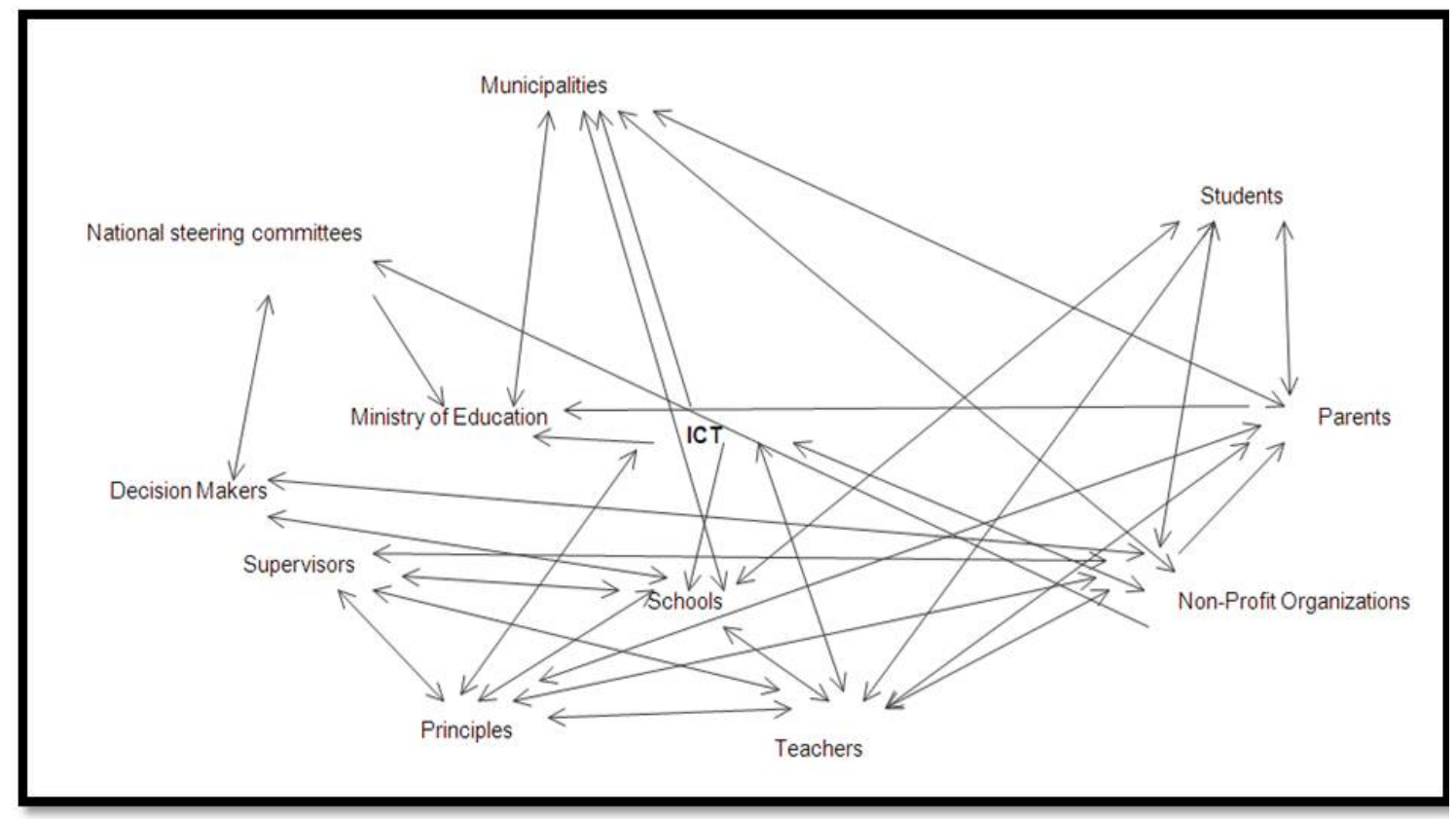

Figure 2: National ICT program network

\section{Actant identity: Non-profit organizations}

The analysis can reveal actants that exist in one of the networks, but not in another. The presence or absence of specific actants serves to explain the difference between the two networks. In the case of the two programs, the analysis revealed similar actants in the two networks. It also revealed that the national program includes an actant which is conspicuously missing from the municipal program: non-profit organizations. These organizations play an important role in the national program as suppliers of infrastructure, of knowhow, and of technological products. In addition, they act as program leaders in some of the local programs. How could this difference be related to the discourse on failure and success in the national program? The key role of these nonprofits in the national program is related to the goal of closing the digital (or ICT) gap. For example, the vision of one of these funds is "to narrow the digital and social gaps in Israel by means of developing highly skilled human capital who espouse both technological and social values" (Tappuah Fund, n.d.). Closing the ICT gap is also mentioned as one of the goals of the national ICT integration program (Chief Committee for Science and Technology Education, 1992). It is reasonable to assume that the non-profits, who collaborate extensively with the Ministry of Education on closing the ICT gap in schools, have an interest in creating extensive public awareness of their work. When we examine their press releases, pamphlets, websites, etc., we find that they target parents and tend to treat them as spectators. They convey to them messages which describe previous ICT integration efforts as not successful by emphasizing the depth of the ICT gap and the need for further investments of money and other scarce resources (Angel, 2010). We do not find evidence for messages from the Ministry of Education which counter these messages of failure that emanate from the nonprofits.

\section{Actant roles: The role of parents}

There are two major categories of actants that an ANT analysis identifies: regular actants and mediators. Mediators are described by Latour (2005) as a special category of actants which role in the network is to modify or transform. When comparing two networks, it is valuable to explore 
not only whether a specific actant exists in both networks, but also whether that actant has the same role in both. If a regular actant in one network is a mediator in another, this could point to an important difference between the two networks.

The analysis revealed that most actants in both networks are regular actants. The most interesting difference in actant roles in the two networks was in regards to the role of the parents. In the national program, parents play the role of regular actors, while in the municipal program, the analysis reveals that their role is that of mediators. Our analysis showed that the parents in the municipal program are mediators who interact with many of the other actants, and should thus be studied closely. The head of the municipal ICT integration project says, "The parents were continually involved in the project, including participation in the selection of the companies who bid to build the project's website." As a part of these relations they have a representative in the program's steering committee, and they partake in the on-site visits of the committee in the schools.

On the other hand, in the national program, parents are actants who receive information from the non-profit organization, from school principals, and from teachers, but we do not find a link of information flow or cooperation with actants such as professional committees, parliamentary committees, or decision makers. Moreover, if we explore the networks for other key sources of information for parents about the program, we find that it is their children who inform them. These children are usually digital natives who perceive their teachers (and often their parents) as digital immigrants (Prensky, 2001; Rushkoff, 1994).

\section{Relationships between actants: Information flow from teachers}

Moving beyond actant identity and role, ANT analysis explores connections between actants. Similarities and differences in these connections, expressed by arrows in the charts, can assist us in comparing the two networks. The analysis of the ICT integration projects detected an interesting difference between the two programs in the manner of information flow between the teachers and other actants. In the national program, teachers transmit messages which express feelings of exploitation, complaints of lack of infrastructure and of compensation (to Ministry of Education supervisors and to school principals), of embarrassment (to students), and of helplessness (to supervisors). On the other hand, in the municipal program we observe a flow of messages expressing a sense of accomplishment, of competence, and of knowledge acquisition (to supervisors, parents, students and principals).

\section{Missing relationships: Assessment and evaluation measures}

An analysis of the relationships between actants in the two networks can also reveal significant missing relationships. The analysis of the ICT integration project networks detected an apparently important lack of evidence for assessment and evaluation measures in the national program. In the municipal program we see relationships of measurement and assessment between the steering committee and various actants such as teachers, principals, and students. In contrast, despite the significant number of documents that describe operational and quantitative goals for the national program, we do not find evidence for processes that evaluate the achievement of these goals. It is interesting to note that this gap has recently been identified in the national project, and several of the new initiatives launched recently include an assessment module carried out by an external assessment and evaluation consultancy.

\section{Technological actants: Teachers and the computer}

One of the important strengths of ANT is that it places human and non-human actants in the same plane and explores the interrelations between them. The non-human actants are often technologies, and ANT analysis can reveal insightful relationships between technologies and human actants. An interesting relationship that was revealed in the comparison of the national and the mu- 
nicipal programs is a significant difference in how the computer is perceived by most of the teachers in the two programs. In the municipal program we observe feelings of ownership, pride, and competence expressed by the teachers towards their laptop computers, while in the national program we observe complaints about lack of confidence, trepidation, and antagonism of the teachers towards the computer and other ICTs.

\section{SCOT Analysis}

As described in the Method section, it became apparent that SCOT analysis can be used to explore the interpretive flexibility of the relevant social groups the ANT analysis revealed. The analysis focused on the flexibility in the interpretation of the concept of ICT by these groups. The groups that were identified and used in the SCOT analysis were, initially, all of the groups included in Figures 1 and 2. In the results presented in Figure 3, the list included only four of the relevant groups. As will be described in more detail later, this subset included the relevant groups which presented interpretive flexibility of one ICT artifact, the interactive whiteboard.

The term used for ICT in the Israeli educational system is "tikshuv". The first half of this word comes from the Hebrew word for communication ("tikshoret") and the second half from the Hebrew word for information technology ("mikhshuv"). The word is used extensively in the educational system. ICT integration projects are titled as "tikshuv projects", and thus the interpretive flexibility associated with this term is revealing. We will use the term ICT as a proxy to the Hebrew term tikshuv.

The analysis of the interpretations of the term ICT by the various groups revealed extensive variability and richness. What follows is a list of terms that were used by various actants, and which exemplify the diversity of interpretations. ICT in general and ICT artifacts were referred to as a (1) status symbol; (2) toy; (3) typewriter; (4) tool; (5) overhead projector; (6) movie projector; (7) copy machine; (8) notebook; (9) book; (10) time sink; (11) dead weight; (12) teacher upgrade; (13) basic skill; (14) babysitter; (15) communication tool, and more. These various interpretations were presented as either positive or negative. For example, "I am not looking for a pretty toy, but rather for a tool". It is not surprising that the differences in the interpretations lead to disagreements about the usage of ICT in the educational system, and these disagreements lead to more failure-oriented discourse.

One of the interesting generalizations that emerge from this analysis is that the more positive interpreters of ICT perceive it as providing novel affordances which were not available to teachers in the past, while the more critical interpreters present ICT as a substitute for something which already existed in the system. Thus, for example a positive interpretation of the computer as "a book" focuses on the new affordance to access hundreds or thousands of books that the student would otherwise not have access to. A negative interpretation would lament the inadequacy of the computer as a substitute for a physical book. The complexity revealed through this initial analysis is extensive, and, for the rest of this paper, we focus on the interpretive flexibility of a single ICT artifact, the interactive whiteboard (IWB).

The IWB is a whiteboard-based computer display. The display is manipulated through touch or other pointing devices which allow activating various applications, as well as writing and saving. It is possible to save whole lessons in multimedia, including the teacher's voice and the written text. IWB based interactive games allow shifting of images on the board, hiding and revealing various elements, and more. The distributors of the IWBs develop or purchase appropriate lesson plans and course materials for the IWB, and teachers who develop such materials are encouraged to upload and share them (Beauchamp, 2004; Smart, n.d.) Studies of successful IWB use emphasize its effect on student attainment when it was used to teach numeracy and literacy in small 
groups. On the other hand, the IWB discourages cooperative learning in small groups and is less effective in special populations (Lewin et al., 2008)

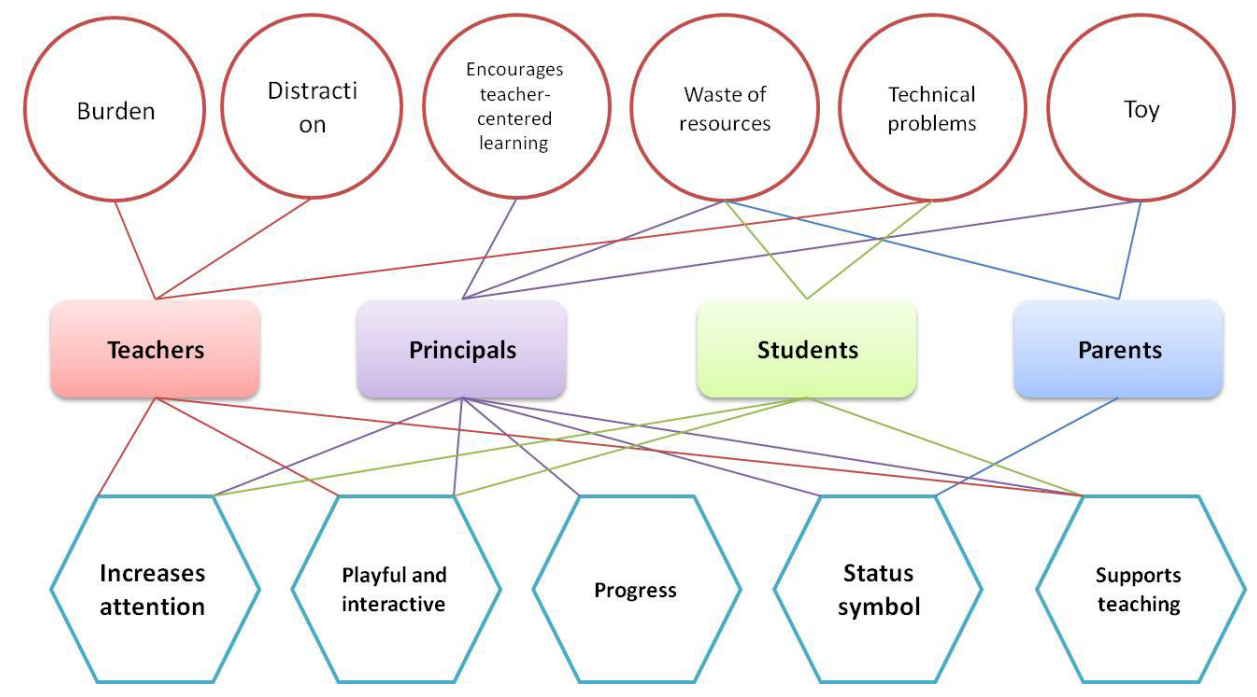

Figure 3: SCOT analysis of positive (hexagons) and negative (circles) interpretations of the interactive white board

The SCOT analysis revealed the interpretive flexibility associated with the IWB. The results are presented in Figure 3.

The figure is arranged to emphasize both the differences between relevant social groups, as well as differences within some of these groups. The four key groups are depicted by rectangles. The positive views are depicted by hexagons (e.g., playful and interactive, status symbol), and the negative views are depicted by the circles (e.g., toy, burden). We can see that each of the four groups has both supporters and opponents of the IWB. An examination of the negative and positive views reveals that in some of the cases opposing views are actually two sides of the same coin. For example, some principals focus not on the pedagogic affordances of the IWB, but rather see it as a status-symbol for the school, like an expensive luxury car. Other principals also do not focus on the pedagogic affordances, but are critical of the IWB and claim that it is merely an expensive toy. Similarly, claims that the IWB focuses student attention on the teacher are countered by the alternative interpretation that the IWB discourages interaction between students and encourages old-fashioned, teacher-centered learning.

The examination of the opposite interpretations of a single artifact also reveals the complex perception of innovation in the educational system. There is no disagreement about the classification of the IWB as an innovation, but there is clear disagreement about the value of this innovation; while some groups perceive innovation as a value by and of itself, others hold the opposing view, a view that educational systems should focus more on the preservation of cultural values and on transferring them to the next generation (Raichel, 2008). Furthermore, in a society like the Israeli society, where innovation is a widely-accepted cultural value (Senor \& Singer, 2009), the educational system finds itself in a conundrum, trying to preserve cultural values while embracing change, which is one of these values. 


\section{Limitations of the Study and Further Research}

Before moving to the conclusion, it is vital to point out some of the important limitations of these findings. Since we are aware of no ANT studies of ICT integration programs in educational systems, this pilot study is, necessarily, limited in several aspects. Firstly, the documents that were analyzed were not collected randomly, and thus cannot be expected to comprise a representative sample of program related documents. This might introduce unexpected bias into the results. We believe that these findings warrant a larger scale collection of documents, as well as active documentation efforts. Secondly, the study is based on a comparison of very different programs, both in scope and in duration. Despite the possible criticism that we are comparing "apples to oranges", it is exactly the similarities and differences between the two programs that allowed us to compare the two networks and identify differences. Many of the differences were not interesting or valuable and were ignored, but other differences that surfaced appear to be significant and pointed to elements in the national program that could be the source of the significant discourse about failure in that program. It is important to point out that these elements now need to be explored in the field, so as to ascertain their role in constructing the discourse about failure. Lastly, readers might question the importance of exploring the discourse on failure of a specific program, versus the exploration of the actual failure. The skepticism about the importance of discourse cannot be addressed in this short format. Nevertheless, this perception is at the heart of the social constructivist approach (Potter, 1996).

There are also limitations related to the SCOT analysis presented here. Although the initial analysis included the attitude of the different relevant social groups to ICT in general, we then focused on only a single artifact, the IWB, for an in depth analysis. Further in-depth analysis of additional artifacts, such as the laptop in 1:1 laptop initiatives (Zucker \& Hug, 2008), should be carried out to expand on these initial findings.

\section{Conclusion}

An in-depth understanding of the success and failure of ICT integration projects in educational systems has both societal and theoretical import. In a society that perceives innovation and progress as imperative for survival, the immediate translation of this imperative is towards investment in ICT. The fact that so many of these investments are later perceived as failures requires a deep investigation of the causes of this perception. Unlike previous studies of success and failure of such integration projects, in this study we apply the tools of science and technology studies (STS) to reveal possible causes of such failure and success.

We start with an ANT analysis of two different ICT integration projects, one of which is associated with more talk of failure and one which is more associated with talk of success. An ANT analysis of the networks of these two projects revealed important differences in the identity of the actants and in the relationships between. These differences could explain the predominance of talk on program failure in the national ICT integration program. The ANT analysis also revealed preliminary evidence for interpretive flexibility of ICT artifacts, a finding which suggested further analysis using social construction of technology (SCOT) analysis methods.

An initial SCOT analysis of the National ICT integration project confirmed that different relevant social groups interpreted the concept of ICT ("tikshuv") in diverse and sometimes even conflicting ways. These findings were further explored through an in-depth analysis of the way relevant social groups interpreted one single ICT artifact: the interactive white-board (IWB). This is a relatively novel technology, which is used in the classroom by students and teachers alike and which is hotly debated. The analysis reveals that even within the same socially relevant groups, both opposition and support for the IWB can be justified using outwardly similar claims about the artifact. 
Taken together, it becomes evident that the STS-oriented analyses led to insights that more traditional approaches did not. By reconceptualizing the users as social actors, rather than the traditional individualistic conceptualization of users (Lamb \& Kling, 2003), our analyses show that information technology, a highly amenable and controllable technology, lends itself to very flexible interpretations, which can easily lead to contrasting views and opinions, as well as contrasting expectations. When the expectations of the different groups are not aligned, it is no surprise that there is no agreement as to the success or failure of ICT projects. Such disagreement inevitably leads to negative interpretations and to an increase in the failure-oriented discourse.

\section{References}

Angel, U. (2010, April 4). I am Udi Angel and I have a dream. Yediot Ahronot.

Armstrong, V., Barnes, S., Sutherland, R., Curran, S., Mills, S., \& Thompson, I. (2005). Collaborative research methodology for investigating teaching and learning: The use of interactive whiteboard technology. Educational Review, 57 (4), 457-470.

Beauchamp, G. (2004). Teacher use of the interactive whiteboard in primary schools: Towards an effective transition framework. Technology, Pedagogy and Education, 13 (3), 720-727.

Chen, D. (Ed.) (2006). Experimental schools. Tel-Aviv: Ramot.

Chief Committee for Science and Technology Education. (1992). Tomorrow 98. Jerusalem: The state of Israel, Ministry of Education and Culture.

Cuban, L. (2010, March 7). Utopians and skeptics on classroom technologies: Where are you on the continuum? Retrieved August 9, 2010, from Larry Cuban on school reform and classroom practice: http://larrycuban.wordpress.com/2010/03/17/utopians-and-skeptics-on-classroom-technologies-whereare-you-on-the-continuum/

Doolin, B., \& Lowe, A. (2002). To reveal is to critique: Actor-network theory and critical information systems research. Journal of Information Technology, June (17), 69-78.

Elbanna, A. R. (2009). Actor-network theory in ICT research: A wider lens of enquiry. International Journal of Actor-Network Theory and Technological Innovation, 1(3).

Genus, A., \& Coles, A.-M. (2007). A critique of Geels' multi-level perspective of technological transition. International Summer Academy on Technology Studies -Transforming the Energy System. Graz: IFZ.

Giere, R. (2006). What everyone should know about STS. Social Studies of Science, 3 (36), 489-493.

Hall, I., \& Higgins, S. (2005). Primary school students' perceptions of interactive whiteboards. Journal of Computer Assisted Learning, 21(2), 102-117.

Hew, K. F., \& Brush, T. (2007). Integrating technology into K-12 teaching and learning: Current knowledge gaps and recommendations for future research. Educational Technology Research and Development, 55(3), 223-252.

Klebl, M. (2008). Explicating the shaping of educational technology: Social construction of technology in the field of ICT in education. Readings in Education and Technology: Proceedings of ICICTE 2008, (pp. 278-289).

Knox, H., Savage, M., \& Harvey, P. (2006). Social networks and the study of relations: Networks as method, metaphor and form. Economy and Society, 35(1), 113-140.

Kozma, R. B. (Ed.). (2003). Technology, innovation and educational change: A global perspective. Eugene, OR: International Society for Educational Technology.

Lamb, R., \& Kling, R. (2003). Reconceptualizing users as social actors. MIS Quarterly, 2(27), 197-235.

Latour, B. (1996). On actor-network theory - A few clarifications. Soziale Welt, 4(47), 369-381. 
Latour, B. (2004). On using ANT for studying information systems: A (somewhat) Socratic dialogue. In C. Avgerou, C. Ciborra, \& F. Land (Eds.), The social study of information communication technology: Innovation, actors and contexts (pp. 62-76). Oxford, UK: Oxford University Press.

Latour, B. (2005). Reassembling the social. New York: Oxford University Press

Latour, B., \& Woolgar, S. (1986). Laboratory life - The construction of scientific facts. Princeton, NJ: Princeton University Press

Law, J. (2007, April 25). Actor network theory and material semiotics. Version of 25th April 2007 Retrieved August 9 2010, from http://www.heterogeneities.net/publications/LawANTandMaterialSemiotics.pdf

Law, N., Pelgrum, W., \& Plomp, T. (Eds.). (2008). Pedagogy and ICT use in schools around the world: Findings from the IEA SITES 2006 study. Hong Kong: CERC-Springer.

Lewin, C., Somekh, B., \& Steadman, S. (2008). Embedding interactive whiteboards in teaching and learning: The process of change in pedagogic practice. Education and Information Technologies, 13(4), 291-303

Melamed, U. (2008, June). Technology in education-theory and the unpracticed practice. Retrieved August 9 2010, from Masa - Mofet around the world: http://portal.macam.ac.il/DbImage.aspx?image=file\&id=1941

Pinch, T. (1993). Turn, turn, and turn again: The Woolgar formula. Science, Technology, \& Human Values, 18(4), 511-522.

Pinch, T. J., \& Bijker, W. E. (1984). The social construction of facts and artefacts: Or how the sociology of science and the sociology of technology might benefit each other. Social Studies of Science, 14, 399441.

Potter, J. (1996). Representing reality discourse, rhetoric and social construction. London: Sage Publications

Prensky, M. (2001). Digital natives, digital immigrants. On the Horizon, 9(5), 1-6.

Raichel, N. (2008). The story of the Israeli education system: Between centralism and distribution, clarity and ambiguity, replication and ingenuity. Jerusalem: Mofet Ins. \& Y. L. Magnes Publications.

Rushkoff, D. (1994). Cyberia life in the trenches of hyperspace. Retrieved August 9, 2010, from http://www.rushkoff.com/downloadables/cyberiabook/

Salomon, G. (2000). Technology and education in the age of information. Tel-Aviv \& Haifa: Haifa University \& Zmora Bitan Publishing.

Senor, D., \& Singer, S. (2009). Start-up nation: The story of Israel's economic miracle. New York: Grand Central Publishing.

Smart. (n.d.). Education. Retrieved August 9, 2010, from Smart: http://www.smarttech.com/us/Solutions/Education+Solutions/Products+for+education/Interactive+whi teboards+and+displays/SMART+Board+interactive+whiteboards/685ix+for+education

Tappuah Fund. (n.d.). Credo and vision. Retrieved August 9, 2010, from Tappuah: http://www.tapuah.org.il/public/index.php?option=com_content\&task=view\&id=12\&Itemid=27

Tatnall, A., \& Gilding, A. (1999). Actor-network theory and information systems research. 10th Australasian Conference on Information Systems (pp. 955-956). Melbourne: Department of information systems, Centre for educational development and support, Victoria University of Technology.

Wild, M. (2006). Technology refusal: Rationalising the failure of student and beginning teachers to use computers. British Journal of Educational Technology, 27(2), 134-143.

Zinder, S. (2006). The computer and the breakage. Shioor Khofshi, 71. 
Zucker, A. A., \& Hug, S. T. (2008). Teaching and learning physics in a 1: 1 laptop school. Journal of Science Education and Technology, 17(6), 586-594.

\section{Biographies}

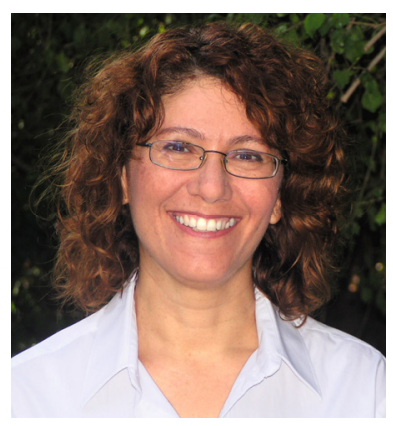

Zvia Elgali (M.S., Clark University) is a graduate student at the Science, Technology and Society Program in Bar-Ilan University in Israel. In the last 15 years she has led ICT integration projects in a wide variety of organizations.

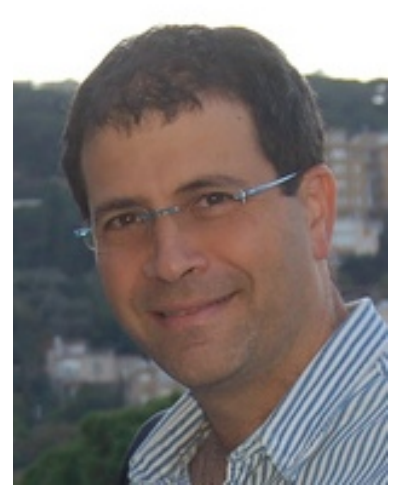

Yoram M. Kalman (PhD, University of Haifa) is a researcher at the Department of Management and Economics, the Open University of Israel. He researches the impact of digital technologies on individuals, organizations, and society. 